\title{
A Review on Customer Relationship Management Practices of Selected Private Banks in Kolhapur City
}

\author{
Miss. Snehal Deepak Kumbhar \\ Chhatrapati Shahu Institute of Business Education \& Research, Kolhapur, Maharashtra, India
}

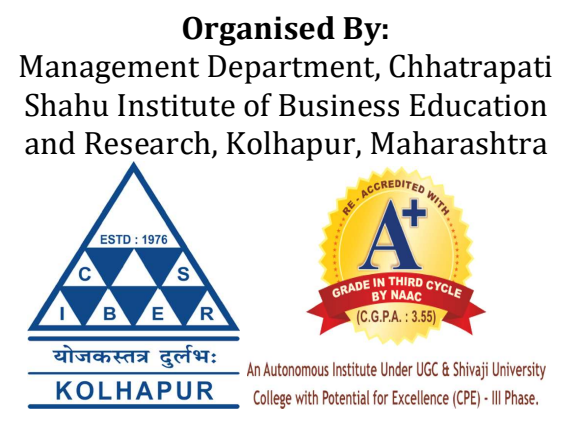

How to cite this paper: Miss. Snehal Deepak Kumbhar "A Review on Customer Relationship Management Practices of Selected Private Banks in Kolhapur City" Published in International Journal of Trend in Scientific Research and Development (ijtsrd), ISSN: 2456-6470, Special Issue | Fostering Innovation, Integration and Inclusion Through Interdisciplinary Practices in Management, March 2019, pp.183-186, URL:

https://www.ijtsrd.c om/papers/ijtsrd23 096.pdf

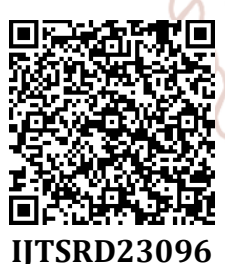

\section{Objectives of the Study}

CRM, the technology, along with human resources of the banks, enables the banks to analyze the behavior of customers and their value. The research work here was undertaken with the intention of studying the Customer Relationship Management practices followed by specific Private Banks with respect to Kolhapur City. Since CRM today plays a vital role in differentiating banks with each other and gaining competitive advantages. The main areas of focus are as the name suggests: customer, relationship, and the management of relationship and the main objectives to implement CRM in the business strategy are:

The prime objectives was supported by the following subobjectives

1. To Study the awareness among the employees about the CRM practices

2. To examine the steps involved in CRM practices
3. To understand who all are involved in the CRM practices

4. To know various CRM initiatives implemented by the Banks

5. To study problems involved in implementation the CRM practices

\section{Literature Review \\ Banking Sector On Review}

Banks are important in mobilizing and allocating savings in an economy and can solve important moral hazard and adverse selection problems by monitoring and screening borrowers and depositors. Besides, banks are important in directing funds where they are most needed in an efficient manner and have direct implications on capital allocation, industrial expansion, and economic growth (Berger, Demirguc-Kunt, and Haubrich 2003; Levine 1997). Banks also play an important role in diminishing informational asymmetries and risks in the financial system. Hence, the 
study of the banking industry and its impact on the economy is of the utmost importance. The effects of concentration and competition on bank performance are pertinent since they have important policy implications. A recent global trend of consolidation in the banking sector has intensified, generating important debates on its effects on the profitability of banks, consumer costs, the efficiency in allocating resources in an economy, and on overall financial stability. In this chapter we present and overview of this literature, starting with a brief survey of the industrial organization theories of the market power and efficientstructure hypotheses that have been put forward to explain the relationship between the structure of the banking sector and its performance in section 2.2. Then, section 2.3 is dedicated to discussing the measurement of banks' efficiency, which is key in the proper assessment of the structure and profitability of the banking industry and, ultimately, of competition conditions. Two main methodologies, parametric and nonparametric, are discussed and analyzed as well as various examples of the empirical literature. Furthermore, banking productivity is presented following the efficiency discussion. The nonparametric Malmquist productivity index is detailed followed by some empirical evidence in the literature. The discussion of the studies about competition in banking follows in section 2.4; here again two broad categories are distinguished; structural models. that follow the market power and efficient structure theories and nonstructural models in line with the new industrial organization theory. Some of the latter models are discussed in this section. Section 2.5 covers some of the most representative empirical studies of this vast and growing literature, which spans various time periods and geographical areas. However, we defer the discussion of the studies for the Mexican banking sector to chapter 4 . Section 2.6 deals with a more recent but growing literature strand on the relationship between bank competition and financial stability; akin to the market power and efficient structure models of the relationship between banking structure and profits, two opposing views of the effect of competition among banks and stability of the banking system have been posed, namely the "competitionstability" and "competition-fragility" views, giving place to growing academic discussions. Some conclusions are presented in the final section 2.7.

\section{Before sales services :}

As in any relationship, it is imperative that a strong foundation of trust is established before moving the relationship forward. In banking, this equates to providing the necessary information required to best use the service opened before trying to sell another product or service.

If a customer opens a new checking account, the services that should be discussed include:
$>$ Direct Deposit
$>$ Online Bill Pay
$>$ Online Banking
$>$ Mobile Banking
$>$ Privacy Protection/Security Services

Education around additional enhancements to a checking account that can further build an engaging relationship include:

Mobile Deposit Capture

$>$ Rewards Program
$>$ Account to Account Transfers

$>$ P2P Transfers

$>$ Electronic Statements

$>$ Notification Alerts

During this relationship growth process, additional insight into the customer's needs should be collected whenever possible with personalized communication reflecting this new insight.

\section{After Sales Services}

After sales service is an integral part of customer service and a key determinant of customer satisfaction and even competitiveness in any industry, manufacturing or service, particularly banking. Most banks have mastered the art of selling their services or the customer processes 'before sales'. Unfortunately, there is an observed lack of emphasis in banking services 'after sales'. Most banks can easily find models and benchmarks of superior after sales service in manufacturing sectors, like autos and household appliances, and in other service sectors like hotels and airlines. These industries have discovered that excellent after sales service is the basis of customer retention, repeat sales, word-ofmouth endorsement, customer loyalty, and future sales. Lack of it or sloppy after sales service would mean the exact opposite: backlash from current customers as well as avoidance of the establishment and its products by future customers. Survival in the next millennium may depend not only on innovative bank products but also on innovative and responsive after sales service.

Many managers would associate after sales service with the handling of customer complaints or warranty returns. Problem solving, while it plays a key role, is not the only component of after sales service. It includes everything that happens, good or bad, to the customer, after every sale or transaction, which may not be a sale, like closing or withdrawing an account, or pre-terminating a loan or time deposit. After sales service therefore means monitoring and analyzing customer satisfaction or dissatisfaction, and doing something about it. Short term activities include sending apologies and solving a problem or correcting an error. Long term ones include process improvement and process standardization. In banking, 'after sales' service should be more accurately referred to as 'after transaction' service, since majority of customer transactions with banks are not selling or buying activities, like opening an account or applying for a loan or credit card.

After sales satisfaction or dissatisfaction can be assessed and acted upon after the sale of a car, the return of a defective car (lemon), when the hotel guest is checking out, or after the restaurant customer has finished his meal. These relatively infrequent transactions from the customer's point of view are identifiable events that are clearly the appropriate time to get feedback after his experience. Unlike in car dealership and the hotel-restaurant business, banking transactions are much more numerous. In a month, a bank client may make scores of ATM or teller-assisted withdrawals and deposits, issue two dozen checks, and use his bank credit card daily. Just when should banks check for customer satisfaction amidst this flurry of activities? The clearest time to check for customer satisfaction, or more precisely, dissatisfaction, is 1) when he lodges a complaint about a bad or erroneous service received, or 2) when he terminates his relationship 
with the bank or his availment of any one of its products or services.

In the first case which demands problem solving or error correction, most banks have systems, procedures, and polices to deal with this 'after sale' situation. However, much remains to be improved even in this most basic case. Resolving an erroneous debit to one's current account or credit card account, or a complaint about delayed statement is not as swift or instantaneous as most customers would want them to be. Disappointingly, resolution usually takes one cycle or a month, accompanied by indifference without any assurance that the same mistake will not recur. Superior after sales service means one-day, same-day, same-hour problem resolution, accompanied by a written apology, explanation and of course the corrected statement. In my opinion, no bank has reached this high level of the most basic of all after sales services. Of course, the ideal bank would aim for and achieve zero error and zero delays in the first place, and would have no need for this type of after sales service.

Rarer than fast problem resolution is the follow-up of lost customers, as in the second case. Banks seldom, if ever, follow up on closed-accounts - current, savings, time, and credit card. Probable reasons for this indifference to lost accounts are 1) closed accounts are so numerous to be monitored, unlike in the case of returned cars or lemons, 2)the amounts represented by these attrition are small, 3) the lost accounts are offset or more than offset by the new accounts opened, 4) management thinks accounts are closed for personal reasons and not because of the bank's failure. Whatever their nature or magnitudes, closed accounts are perfect opportunities to discover the root cause of customer dissatisfaction, if indeed it was the cause of the termination, and take action or improve service to prevent future attrition or even woo back the lost customer. It is prudent, in the spirit of continuous improvement, to always assume that accounts are closed because services are below expectation or competitors offer something better. Massive withdrawals, infrequent deposits, or inactive accounts, and other customer activities or in activities that are a prelude to termination of service should also be examined for after sales dissatisfaction.

As important as customer dissatisfaction is customer satisfaction after sales. A bank should learn to ask satisfied customers what it did right, and not only what it did wrong to them. Banks should get immediate and regular feedback from new account holders, new cardholders, and new loan applicants about their level of satisfaction, reasons for choosing the bank, and their expectation. The bank's best practices, as determined by its satisfied customers, should be standardized and adopted bank-wide. The highest form of after sales service is opportunity seeking and not problem solving.

\section{Methodology Adopted}

1. Research Methodology:

Depending on the needs and levels of sophistication, the research methodology is used to collect the required data for fulfilling the objectives of the research undertaken. There are several methods of data collection.

\section{Survey Method:}

This method was adopted by the researcher to collect information with respect to customers attitude, preferences, buying behavior, likes and dislikes etc. Under this method two comprehensive questionnaires were designed, one for the Banks Customers, to get their response towards Banks and other for the Bank Management, to understand their current efforts and practices towards Customer Relationship Management.

\section{$>$ Personal Discussion:}

Personal discussion gives depth input to the actual problem as each of the candidates is personally handled and from the expression given one can judge and reality of the problems and also it depthless. Few of the customers and employees of the companies were personally interviewed and the results were found our

\section{$>$ Observation Method:}

Observation method of data collection was adopted to obtain data due to unwilling on the part of the people to reveal certain facts. This method helped the researcher to crossexamine the various responses received through the survey method. This was done by personally visiting the offices and observing not only the walk-in customers but also the behavior of the frontline employees in handling the customers queries and complaints.

\section{Sources of Data Collection:}

The information required for further study was collected by the researcher though two sources:

\section{Primary Source:}

Primary data was the fresh data which was collected directly from the field through:

A. Personal Observation

B. Personal Discussion

C. Interviews

D. Questionnaires

\section{Secondary Data:}

Secondary data can be obtained at lower cost as compared to primary data. As the efforts, time and money involved is less. Moreover it is readily available in the form of in-house publications and also on the Internet. It is more reliable and required for the study of the researcher.

Following sources were used for collecting data:

A. Published theoretical concepts from the books of SIBER library

B. Magazines and other relevant material of the banks

C. Internet

D. Bank magazines

\section{Sampling Design:}

Sampling plan is an important aspect in research which calls for 2 decision

They are as follows:

\section{Sampling Unit:}

Sampling unit means: "Who is to be Surveyed?"

Customer and Employees of different Private Bank such as ICICI Bank, HDFC Bank, Yes Bank, Axis Bank and Kotak Mahindra Bank, Karnataka Bank, Karur Vyasa Bank, Lakshmi-Vilas, Bandhan Bnak is choose for survey and further study. And even SWOT analysis will do. 
International Journal of Trend in Scientific Research and Development (IJTSRD) @ www.ijtsrd.com eISSN: 2456-6470

2. Sample Size:

Sample Size means: "How many people to be surveyed?"

In this 9 Private Sector Banks were taken into consideration. To know CRM approach and practices, its implementation by these banks and rate of satisfaction levels among the customer, sample chosen was randomly 10 customers and 2 employees of each bank. The Total Sample Size was 108. The selection of these Banks were done because of their Balance-sheet Progress and Success

\section{Hypothesis I \& II}

1. Null Hypothesis H0: "There is no significant relationship between employees efficiency \&CRM Implementation"

Alternative Hypothesis H1: There is significant relationship between employees efficiency \& CRM implementation

2. Null Hypothesis H0: "There is no relationship between Awareness of CRM Practices \& employees performance

Alternative Hypothesis H1: "There is relationship between Awareness of CRM Practices \& employees Performance.

\section{Scope of the Study :}

The scope of the study us limited with references to the following

\section{> Topical Scope:}

The topic selected by the researcher for study is, “ $\mathbf{A}$

Study Of Customer Relationship Management
Kolhapur City". To stay in the race role of CRM in Banks is very important, whether private or public. But CRM is only a small part of overall marketing process so the topical scope is limited.

$>$ Geographical Scope:

The research study is confined to 9 Private Banks in Kolhapur City. As per the methodology the respondents selected for data collection were restricted only to these five banks. So the geographical scope is also limited.

\section{$>$ Analytical Scope}

Analysis of the study is based on the pre-determined objectives set by the researcher so the scope is limited.

\section{$>$ Functional Scope:}

Functional Scope is also limited as it depends upon the Analysis done

\section{Reference}

[1] https://www.google.com/search?q=what+is+crm+in+b anking+sector\&oq

[2] https://www.toppr.com/bytes/collection-of-data/

[3] https://www.justdial.com/Kolhapur/Private-SectorBanks/nct-11190579

Copyright (C) 2019 by author(s) and International Journal of Trend in Scientific Research and Development

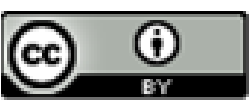
Journal. This is an Open Access article distributed under the terms of the Creative Commons Attribution License (CC BY 4.0) (http://creativecommons.org/licenses/by/4.0)

\section{(CRM) In Private Banks With Respect To}

